\title{
Morphology and fracture effects of the hamulus pterygoid: a literature review of the last 49 years
}

\section{Morfología y efectos de fractura del hamulus pterygoid: una revisión de la literatura de los últimos 49 años}

\author{
DOI: $10.46814 /$ lajdv3n1-041
}

Recebimento dos originais: 30/10/2020

Aceitação para publicação: 23/12/2020

\author{
Polyanne Junqueira Silva Andresen Strini \\ PhD, Federal University of Uberlândia - UFU, Uberlândia, MG, Brazil \\ Address: Rio Preto Street, 178, Lídice, Uberlândia - MG \\ Paulinne Junqueira Silva Andresen Strini \\ PhD, Federal University of Uberlândia - UFU, Uberlândia, MG, Brazil \\ Address: Rio Preto Street, 178, Lídice, Uberlândia - MG
}

\begin{abstract}
The hamulus pterygoid consists in a relevant anatomical structure, important for fixation of several tendons and muscles, keeping the integrity of soft palate and pharynx. A literature review was conducted in order to investigate the morphology and effect of hamulus pterygoid fracture in clinical manifestation and its relationships with other orofacial components. A literature search was conducted, using Pubmed and Bireme data bases, and covering the time period 1970 to 2019. The Key words for the research were hamulus pterygoid, pterygoid fracture and hamulus pterygoid fracture, resulting in 440 articles, being 41 initials selected. Among them, just 31 were included in the analysis and 08 of the articles were not available through our library system or were in volumes before our holdings began. The remaining were excluded when they weren't in English idiom, or when didn't talk about morphological, functional or damages in the hamulus pterygoid. In this context, it may be observed a scarce number of works about the hamulus pterygoid, with doubts in relation to its morphology and functional aspects and how diagnostic its lesions and consequences.
\end{abstract}

Key words: Hamulus Pterygoid, Pterygoid Fracture, Hamulus Pterygoid Fracture.

\section{RESUMEN}

El hamulus pterygoid constituye una estructura anatómica relevante, importante para la fijación de varios tendones y músculos, manteniendo la integridad del paladar blando y la faringe. Se realizó una revisión bibliográfica para investigar la morfología y el efecto de la fractura del hamulus pterygoid en la manifestación clínica y sus relaciones con otros componentes orofaciales. Se realizó una búsqueda bibliográfica, utilizando las bases de datos Pubmed y Bireme, y abarcando el periodo de tiempo de 1970 a 2019. Las palabras clave para la investigación fueron hamulus pterygoid, pterygoid fracture y hamulus pterygoid fracture, dando como resultado 440 artículos, siendo 41 iniciales seleccionados. Entre ellos, sólo 31 fueron incluidos en el análisis y 08 de los artículos no estaban disponibles a través de nuestro sistema de bibliotecas o se encontraban en volúmenes anteriores a nuestras existencias. Los restantes fueron excluidos cuando no estaban en idioma inglés, o cuando no hablaban de daños morfológicos, funcionales o en el hamulus pterygoid. En este contexto, se puede observar un escaso número de trabajos sobre el hamulus pterygoid, con dudas en relación a su morfología y aspectos funcionales y como diagnóstico de sus lesiones y consecuencias. 
Palabras clave: Hamulus Pterygoid, Fractura del Pterigoideo, Fractura del Hamulus Pterygoid.

\section{INTRODUCTION}

The sphenoid bone consists in a reference structure for connection between almost all the other cranial bones, situated at the base of the skull in front of the temporal and basilar part of the occipital. It is divided into a median portion or body, two great and two small wings extending outward from the sides of the body, and two pterygoid processes which project from it below and consist of a lateral and a medial plate. The medial plate curves lateralward at its lower extremity into a hook-like process, the pterygoid hamulus $(\mathrm{PH})^{1}$, which shows a close relationship with important anatomical structures and your damage can affect their functions with serious consequences.

Between structures in close relationship with $\mathrm{PH}$, is observed providing a support point for fixation of the tensor muscle of the soft palate and the pterygomandibular ligament, with special importance for dentistry and health professionals. This muscle tightens the palate and opens the Eustachian tube during stomatognathic functions. Alterations in $\mathrm{PH}$ or related structures may provoke signals and symptoms that include pain, inflammation, edema, and others common to many pathologies $^{2}$.

Considering all the anatomical e functional importance of the pterygoid process, in specially the HP, and the near relationship observed with vital structures, an evaluation about these aspects have presenting to be of extreme necessity. Also, the understandings of the consequences of its lesions and the care during clinical and surgical procedures have showing a great significance for professionals in the major of the healthy areas. Thus, the aim of this work was reviewed the literature in order to investigate the morphology and effect of hamulus pterygoid fracture in clinical manifestation and its relationships with other orofacial structures.

\section{EXPERIMENTAL SECTION}

A literature search was conducted, using public data bases, and covering the time period 1970 to 2019. The Key words used in the present study were hamulus pterygoid, pterygoid fracture and hamulus pterygoid fracture, researched individually and in order mencioned. First, the articles were researched in Pubmed and then in Bireme data bases. The abstracts were read and the articles in accordance with the objective were initially selected. In the second moment, the complete text was read and the articles that attended the including and excluding criteria were included in this work.

It was included in this research, the articles containing information about the morphology and effect of hamulus pterygoid fracture in clinical manifestation and its relationships with other orofacial 
components. However, were excluded articles that weren't in English idiom, or when didn't talk about morphological, functional or damages in the hamulus pterygoid, not available through our library system or were in volumes before our holdings began.

\section{RESULT AND DISCUSSION}

In accordance whit databases research, was found a total of 440 articles, being 41 initials selected. Among them, just 31 were included in the analysis and 08 of the articles were not available through our library system or were in volumes before our holdings began (Table 01).

Table 1. Search results from different databases about hamulus pterygoid process between 1970 and 2019 years.

\begin{tabular}{lllll}
\hline Database & Keywords & Results & Selected & Included \\
\hline \multirow{3}{*}{ Bireme } & $\begin{array}{l}\text { 1. hamulus pterygoid } \\
\text { 2. pterygoid fracture } \\
\text { 3. hamulus pterygoid fracture }\end{array}$ & 228 & 01 & 01 \\
& $\begin{array}{l}\text { 1. hamulus pterygoid } \\
\text { 2. pterygoid fracture } \\
\text { 3. hamulus pterygoid fracture }\end{array}$ & 212 & 40 & 30 \\
\hline & Total & $\mathbf{4 4 0}$ & $\mathbf{4 1}$ & $\mathbf{3 1}$ \\
\hline
\end{tabular}

When analyzing the articles found in literature search it was possible observed the morphological and functional characteristics about pterygoid hamulus ( $\mathrm{PH})$ and the risks involved in it damage. The $\mathrm{PH}$ is describing like a structure arising from the medial lamella of pterygoid process, curving laterally and forwards $s^{3,4,5}$. Thus, is describe like a bone process located at lower end of the medial plate of the pterygoid process of the sphenoid bone ${ }^{1,2}$. Several doubts exist in relation to its morphology and functional significance. However, its topographical proximity to significant hard and soft tissues like distal end of the upper dental arch, maxillary tuberosity, blood vases and muscles ${ }^{4}$, brings interest of all healthy areas that are involved with this region, become its study of extreme necessity for professionals.

Measurements of the PH were done with a sliding gauge in adult, children and animals' skulls, as well sections cut from specimens embedded in methyl methacrylate were examined histologically. The average measurements are: length $7.2 \mathrm{~mm}$, sagittal breadth $1.4 \mathrm{~mm}$, transverse breadth $2.3 \mathrm{~mm}$. Also was observed that the PH of children is the same as those of adults, although smaller. The sections show that the medial cortical lamella is thicker than the lateral, the medial gradient angle of the collagen fibers is smaller than that of the lateral. A few muscles take origin from the hamulus, in particularly the tensor veli palatini that turns around the neck and a few of its fibers take origin here ${ }^{4}$.

The anatomy of HP was studied using 3D cone beam computed tomography (CBCT) images in 396 sides of 198 patients. The analysis was done by a software able to generate 3D hard tissue surface 
representations of PHs. The measurements of left and right sides were 1.72 (SD 0.94) and 1.87 (SD 1.17) $\mathrm{mm}$ width, and lengths were 5.48 (SD 1.94) and 5.40 (SD 2.0) $\mathrm{mm}$, respectively, with no significant difference ( $p>0.05$ ). The authors still observed that all PHs were inclined toward the lateral side in the coronal plane, whereas PHs tended to incline toward the posterior rather than anterior in the sagittal plane ( $78 \%)$. In this sense, it was possible to affirm that knowledge about morphology of HP is essential for understanding tomography images and provides information about its characteristics, which is important in the diagnosis dysfunctions of oral cavity and pharynx ${ }^{6}$. So, the learning about its technical features and relationship with neighbor structures was fundamental to clinical and radiologists ${ }^{6}$.

A relation exists between the pterigoyd process and pterygopalatine fossa, which is situated between the bone boundaries of the posterior maxilla and the lateral pterygoid plate. In this local, the third part of the maxillary artery terminates by dividing into a many branches that leave the pterygopalatine fossa through their respective foraminae and fissures, and include the posteriorsuperior alveolar artery, infraorbital artery, descending palatine artery, artery to the foramen rotundum, artery of the pterygoid canal, the pharyngeal artery and the sphenopalatine artery ${ }^{7}$ Near of this region, still found the nasopharyngeal cavity, like a continuation of the nasal cavities and extends from the posterior border of the nasal septum to inferior border of the soft palate ${ }^{7}$, and represents a component which can suffer if the musculature is compromise.

A relationship of the greater palatine foramen so has been observed to the pterygoid hamulus and molar teeth during analysis of negroid skulls ${ }^{8}$. Another anatomical aspect to be remembered in this location is related to the lateral and medial pterygoid muscles that arise from pterygoid plate and maintain contact with infra-temporal fossa. In this place, is noted a complex venous network, the pterygoid plexus of veins ${ }^{9}$, which can be affected by maxillary tuberosity and hamulus fractures, with largely occurrence in surgical dental practice.

The biomechanically of PH is in a peculiar situation. Putz \& Kroyer (1999) ${ }^{4}$ divided the PH following the terms, the base: Basis; body: Corpus; sulcus: Sulcus; neck: Collum and head: Caput of the Hamulus, considered important in load functional distribution. The body of PH is subjected to greater loading in the medio-dorsal direction, but the head is freely pulled away laterally and caudally. This fact is observed in despite of the attachment of a number of muscles, that exert a pull in a dorsocranial or in a medial direction. The pterygomandibular raphe also applied a latero-caudal tension. An adipose tissue was noted at the hamulus, providing lubrication for the tendinous fibers of the $\mathrm{m}$. dilatator tubae as they round it, decreasing the friction on this tendon, protecting from injury due to abrasion and thus requiring less force to achieve tubal dilation ${ }^{10}$. 
The function of several muscles also depends of the position, length and inclination of $\mathrm{PH}^{5}$, especially in relation to the width of the hard palate. Some muscles and tendons related to it include the $\mathrm{m}$. tensor velli palatine, $\mathrm{m}$. constrictor pharyngis superior (pars pterygopharyngea and pars buccopharyngea), raphe pterygomandibulares, m. buccinators, m. pterygoideus medialis ${ }^{4}$ and palatopharyngeus ${ }^{5,1}$. The superior constrictor muscle of the pharynx has its origin along the medial pterygoid plate and along the pterygomandibular raphe stretching from the pterygoid hamulus to the retromolar triangle of the mandible ${ }^{11}$. Some of these muscles contribute to the separation of the oral from the nasal cavity during sucking and swallowing ${ }^{5}$, simultaneously moving the bolux downward ${ }^{11}$. This fact also depends by the elevations of the soft palate, which occurs, especially, in contration of levator veli palatine. This muscle takes origin in base of skull, in pars petrosa ossis temporalis, and runs downwards and joins the palatal aponeurosis ${ }^{5}$.

The tensor veli palatini muscle originates from the spina ossis sphenoidalis, medial to the oval foramen and foramen spinae, and from the fossa scaphoidea and lateral wall of the pharyngeal tube. The part originating in tubar wall is fixed to the hamulus and functions as dilatators of the pharyngeal tube $^{5,12}$. The tendon of the tensor veli palatini turns round or is redirected by the hamulus ${ }^{4,12,13}$ and this muscle not only uses the HP to change direction, but also takes partial origin from its base ${ }^{4}$ and continues as a flat tendon to form most of the palatal aponeurosis ${ }^{1,5,12,13}$. Notably, secondary insertions were found on the maxillary tuber (33.6\%) and/or in the submucosal tissue near the palatoglossal arch (37.8\%) (Abe et al., 2004). It appears to act as the dilator tubae ${ }^{14}$, and its contraction produces the tension and elevation of the soft palate ${ }^{5}$.

Additionally, Okada et al. (2018) ${ }^{15}$ related that the infero-lateral muscle bundles of the tensor veli palatini didn't turn medially at the pterygoid hamulus but distributed laterally and continuous with the buccinator and its contraction, in cooperation of others muscles in this area, contributes to the dilating mechanism of the Eustachian tube ${ }^{15}$. During normal swallowing, the tensor veli palatine, and possibly the levator veli palatine, opens the lumen of the Eustachian tube that equalizes pressure between the middle ear and the atmosphere, allowing ventilation. Thus, any abnormalities of insertion of the tensor as in cleft palate, poor development of the muscle or surgical damage to the muscle or the pterygoid hamulus could alter Eustachian tube physiology ${ }^{12}$. The course and action of tensor veli palatine can be altered at the time of surgical repair of the palatal cleft by division of its tendon or by fracture of the pterygoid hamulus, around the tendon passes. However, some authors affirm ${ }^{12}$ that fracture of HP and disturbance of the integrity of the tensor veli palatine tendon during soft palate, closure does not significantly alter the state of middle ear disease ${ }^{12}$.

Alterations in morphology of the HP, mainly changes in its shape, are related to changes in the functions of the pharyngeal and palatal muscles in deglutition. In this context, the contractions of theses 
muscles are able to provoke the elevation and the constriction of the pharyngeal tube ${ }^{5}$. In movements of the pharynx, the pars buccopharyngea of the m. constrictor pharyngis superior, show a significative function. This muscle take origin from the raphe buccopharyngea, which consist in a tendinous inscription from the tip of the hamulus and fixation in mandible. The raphe exerts a mechanical loading during chewing and swallowing, being able to becomes longer the HP in adults. After the loss teeth, in old age, lack of biomechanical loadings on the pterygoid hamulus can causes its shortening 5 . The superior constrictor muscle of the pharynx can contract and execute its appropriate function after $\mathrm{PH}$ reaches the proper length and the pterygomandibular ligament is firmly adhered to it and to the mandible ${ }^{2}$.

The spatial relations of the pterygoid hamulus with hard palate were investigated on 65 skull bases. The width of the hard palate in the choanal region was smallest in children compared with adult skulls. Children had the shortest hamulus and its length increased in the adult age group and then again decreased in the 60-100 age group. The distance between the tips of the contralateral hamulus and their lateral inclination from the perpendicular plane were also greater in the adult age group than either in children or the elderly. Therefore, this study showed that the anatomical measures of the pterygoid hamulus and its relation to the surrounding structures change with age and occur with the changes in the function of pharyngeal and palatal muscles in deglutition and may have clinical relevance for sleep apnea and snoring ${ }^{5}$. Oz et al. (2016) ${ }^{16}$ affirm that PH length is inversely associated with sleep apnea severity. The authors analyzed the apnea hypopnea index with a PH length and a statistically significant association was observed. They concluded that study of its length could be a future supplementary measurement to help clinicians to stratify and determine the treatment options for patients with obstructive sleep apnea ${ }^{16}$.

When the structures of this region are analyzed, a concern about the consequences of trauma and lesions must be considered. The sphenoid bone fractures are the most frequent skull fractures and their patterns have predictive value regarding patient mortality and fracture complications. In a study about transsphenoid basilar skull fractures, in patients with serious head trauma, the authors observed that fractures occur along reproducible lines of weakness, including a coronal plane through the anterior sphenoid body and pterygoid plates, a coronal plane through the posterior sphenoid body and clivus, and the sphenopetrosal synchondrosis ${ }^{17}$.

The most common type of lesion in the sphenoid bone includes the fractures in this structure and in related osseous components, which can bring serious injure. In a case report, an extraction of an upper second molar was complicated by a maxillary tuberosity fracture. The patient was referred to a specialist unit and the fragment was removed under general anaesthetic required the control of hemorrhage deep within the infratemporal fossa. The tooth and bone fragment couldn't be removed 
under local anaesthesia because of pain, brisk bleeding and tethering by the lateral and medial pterygoid muscles ${ }^{9}$. After examination, was observed an attached bone together the teeth, including the maxillary tuberosity, the pyramidal process of the palatine bone and a small portion of the lateral pterygoid plate ${ }^{9}$.

In another study, the posterior maxilla and pterygoid plate fractures, caused by a facial trauma in a motor vehicle accident, can lead nasopharyngeal soft tissues swelling, most likely due to hemorrhage and/or edema resulting in severe narrowing of the nasopharyngeal cavity. This fact could difficult in elective nasogastric tube and endotracheal tube intubation via the nasopharyngeal route ${ }^{7}$, demonstrating the major importance of this area in healthy areas.

The symptoms showed by a patient in a case of unilateral fracture of the pterygoid process, include a primary malocclusion as well as paresthesia of the major part of the maxillary nerve. The patient's difficulties in swallowing presented could be explained by functional disturbance of the muscles in the infratemporal fossa due to the trauma. A functional disorder in the superior constrictor muscle of the pharynx and tensor veli palatine may cause considerable difficulties in swallowing. An intermaxillary fixation into correct occlusion was done ${ }^{11}$.

The fractures of pterygoid plate have been associated with Le Fort II, Le Fort III and zygomaticomaxillary compound fractures. An inability to close the mouth and subsequent open-bite deformity is noted and could was attributed to spasm and possible laceration of some fibers of medial and lateral muscles ${ }^{18}$. In major of cases, a computer tomography is necessary to identify fracture of the pterygoid processes and treatment conservative is indicated ${ }^{18}$.

Additionally, pterygoid process fractures were studied in association with maxillary transverse fractures, in 100 patients using image processing software. It was observed that pterygoid process fractures were near to the upper edge of the pterygoid fossa and pneumatization of the pterygoid process is a risk in fractures involving the sphenoid sinus floor and consequences of surgical procedures ${ }^{19}$. Also, the incidence of posterior maxillary fractures involving the posterior maxillary sinus wall, pterygoid plate or both was studied in CT images in patients with mandibular fractures demonstrating association between them ${ }^{20}$. In cases of pterygoid fractures, consequently hamulus was involved, and many fractures may be present.

In that way, pterygoid plate fractures have been associated with fractures of the mid-face and skull base. When noted pterygoid plate fractures in images, probably others fractures may be identified $^{21}$. Truoung at al. (2014) ${ }^{21}$ evaluated isolated lateral pterygoid plate fractures in conjunction with mandible fractures, by means of computed tomography and concluded that the association between them may be caused by force transduction through the medial and lateral pterygoid muscles when acute displacing force is placed on the mandible, suggesting the necessity of integral clinical and radiography analyses of the patient with fractures ${ }^{21}$. Winegar et al. $(2013)^{21}$ clarify that tomography is 
the major form to analyses facial fractures, involving many structures, specially in cases of trauma. They appear with several bones affected, including sphenoid and hamulus ${ }^{22}$.

In the literature, have been described a case in which a fracture of the maxillary tuberosity resulted in deafness because of disruption the pterygoid hamulus and tensor veli palatine, collapsing the opening of the Eustachian tube. In addition, a permanent restricted mandibular movement was noted due to disruption of the pterygoid muscles and ligament ${ }^{9}$.

In the surgical repair of cleft palate, some surgeons fracture the hamulus processes and dislocate the $\mathrm{m}$. tensor veli palatine away from the process in order to minimize tension on the repair and thereby presumably lessen the probability of dehiscence ${ }^{13}$. In a study about performance of palatoplasty, no statistically differences in measured surgical, otolaryngological or preliminary speech outcomes were found between the groups of patients who did and did not receive hamulus fracture. Therefore, the authors were considered unable to measure a benefit of hamulus fracture and couldn't recommend its performance on the basis of its historical intent or theoretical rationale ${ }^{13}$.

The effects of the pterygoid hamulus fracture on middle ear disease during palatoplasty were commented by Noone et al. (1973) ${ }^{12}$. In their study, each patient underwent only unilateral hamulus fracture, which was randomly assigned. Eighty-nine patients were evaluated with audiograms and clinical examinations over a 3-year follow-up period. They concluded that the hamulus fracture and, thus, disturbance of the tensor veli palatine tendon during soft palate closure does not significantly alter the state of middle ear disease ${ }^{12}$.

In addition, the relationship of hamulus fracture with the postoperative state of middle ear in cleft palate children was studied in fifty cleft palate patients, with an age range of 10 months to 5 years old and compared with a control group. The authors concluded that hamulotomy does not have any effect on the hearing ability in cleft palate population, and the procedure can be be performed for tension-free closure during palatoplasty ${ }^{23}$. Considering the researches about the consequences of fractures in hamulus during palatoplasty, still remain several contradictions and others studies are fundamental to clarify it.

The morphological alterations on hamulus are able to bring important disturbance in the area. There are a few anatomic disorders which cause pain or discomfort in the regions of the soft palate and pharynx. Elongation of the pterygoid hamulus is a rare syndrome that shows various and complex symptoms and its treatment can be either conservative or surgical ${ }^{24,25}$. The diagnose of pterygoid hamulus syndrome is hard and can cause long-term suffering, like reported in a case of 30 year old patient with history of discomfort and pain ${ }^{25}$.

In another case report, the patient noticed swelling and a painful sensation in the region of left palate and experienced pain radiating from the buccal region the temporofrontal region. Clinical oral 
examination revealed bilateral swellings of the soft palate, just posterior to palpation maxillary tuberosites and the overlying palatal mucosa was normal. On palpation, the mass under the soft palate mucosa was hard and rigid and appeared to be the pterygoid hamulus. These findings suggested that the pain was associated with mechanical stimulation to the surrounding tissues by the elongated pterygoid hamuli which disturbed the function of the tensor veli palatini muscle ${ }^{25}$. Another case is also reported of a patient suffering from untraceable pain in the palate and the hyperplastic pterygoid hamulus appeared to be the cause of this discomfort, indicating that this structure can be responsible for atypical pain ${ }^{27}$.

Frequently, several pain syndromes exhibit similar symptoms. One such disorder is bursitis of the pterygoid hamulus ${ }^{1}$. Consist in a rare disorder with symptoms in the palatal and pharyngeal regions $^{27}$, including pain in soft palatal, ear, throat, maxillary pain, besides difficulty and pain on swallowing. This disorder is often misdiagnosed as otitis media ${ }^{1}$, demonstrating the great importance of the knowledge of this area. This bursitis is characterized by an inflammation of bursae located between the tendon, muscle, and bony prominences and be considered in the differential diagnosis of craniofacial neuralgia, temporomandibular joint dysfunction, and chronic craniofacial pain ${ }^{28}$.

The topography of PH may predispose for developing the bursitis in this structure like demonstrated in a study conducted based on the morphometric analysis of $100 \mathrm{PHs}$ on cone beam computed tomography (CBCT) scans. The authors related a numerous significant correlation between the morphometric parameters and then, concluded that an extensive medial deviation of the pterygoid hamulus in the frontal can cause main pathogenic factor in PH's bursitis ${ }^{29}$.

The treatment of bursitis of hamular process may be conservative or surgical, with a simply of blunt dissection and exposure of the hamulus ${ }^{1,27}$. If the etiologic factor of bursitis is osteophytic formation on the hamulus or hypertrophy of the bursa, resection of the hamulus is usually the preferred surgical treatment ${ }^{27}$. Clinical signs and symptoms of this bursitis are diverse and multifaceted that can sometimes demand services of clinicians across various specialties considering the anatomic density of the region. Care must be taken to avoid delay, misdiagnosis, and overtreatment ${ }^{28}$.

Some patients with temporomandibular joint dysfunction and/or myofascial pain syndrome present an extensive and complex series of symptoms and complaints. In a case report, the patient in this condition was treated only for one of her numerous complaints that is a burning sensation on her palate when she touched the right tuberosity area with her tongue or finger. A surgical exposure of the hamulus confirmed a fibrotic enlargement and involvement of the bursa. The excess fibrous tissue was removed, and the bursa was slit along its long axis to allow freedom of the tensor veli palatine muscle during contraction. In addition to the bursitis, an osteophyte (bony spicule) was discovered on the 
medial aspect of the hamulus, extending into the muscles of the soft palate. The osteophyte was removed with a bone file ${ }^{30}$.

A study examines the comorbidity of pterygoid hamulus pain in 464 subjects with temporomandibular disorders (TMD), verifying a total of 92 patients with pain in the palate or throat, which correspond an almost $20 \%$ of the incidence of pain. Pain in the pterygoid hamular area can arise from bone, muscle, bursa and the mucosa. Thus, an evaluation of patients suspected of TMD should include a review of the pterygoid hamular area as a contributing etiology especially those presenting with posterior palate and throat pain ${ }^{31}$.

Anatomic variations of the pterygoid hamulus of the sphenoid bone also may be related to lesions observed in the posterior palatal mucosa. An investigation of this region was undertaken in 60 dental patients and the symptoms most commonly associated with lesions relating to the hamulus are pain when chewing or swallowing, and pain associated with finger or tongue pressure applied to this area. During clinical examination, edema, firm elevation, erythema, and occasional ulceration may be present. The authors emphasize that an appreciation for the implications of the pterygoid hamulus is an important aid in the diagnosis of lesions in the posterior palate ${ }^{3}$.

In this way, the knowledge of health professionals about the pterygoid hamulus $(\mathrm{PH})$ is essencial for understanding its anatomical and functional relationship with neighboring structures and to contribute for diferencial diagnosis, clinical conduct and prevention of lesions in face and neck regions $^{2}$. In order to provide such more information about anatomy, functional aspects, risks and consequences about HP, future research showed necessary to clarify remnants doubts.

\section{CONCLUSIONS}

Based on the works exposed, the pterygoid hamulus is a strategically osseous structure located near of essentials anatomic components and potentially endangered in surgical operations. The injuries and morphological alterations could be able to bring signs and symptoms, demonstrating the great importance involved in its knowledge for healthy professionals and the necessity of preventive procedures to avoid complications. In this context, it may be observed a scarce number of works about the hamulus pterygoid, with doubts in relation to its morphology and functional aspects and how diagnostic its lesions and consequences. 


\section{REFERENCES}

Shankland WE. Pterygoid hamulus bursitis: One cause of craniofacial pain. Journal of Prosthetic Dentistry 1996; 75: 205-10.

Barchetta N F, Oliveira R L B de, Silveira V Á S et al. Clinical and morphofunctional aspects of pterygoid hamulus: literature review. Brazilian Dental Science 2015; 18 (4): 5-11.

Charbeneau TD, Blanton PL. The pterygoid hamulus. A consideration in the diagnosis of posterior palatal lesions. Oral Surgery 1981; 52(6): 574-576.

Putz R, Kroyer A. Functional morphology of the pterygoid hamulus. Annals of Anatomy 1999; 181: 85-88.

Krmpotic'-Nemanic'J, Vinter I, Marus 'ic' A. Relations of the pterygoid hamulus and hard palate in children and adults: Anatomical implications for the function of the soft palate. Annals of Anatomy 2006; 188: 69-74.

Orhan K, Sakul B U, Oz U et al. Evaluation of the pterygoid hamulus morphology using cone beam computed tomography. Oral Surgery, Oral Medicine, Oral Pathology, Oral Radiology, and Endodontology 2011; 112(2): 48-55.

Wittram C. Nasopharyngeal cavity narrowing associated with posterior maxilla and pterygoid plate fracture: report of three cases. European Journal of Radiology 1997; 24: 222-226.

Langenegger JJ, Lownie JF, Cleaton-Jones PE. The relationship of the greater palatine foramen to the molar teeth and pterygoid hamulus in human skulls. Journal of Dentistry 1983; 11(3): 249-56.

Shah N, Bridgman JB. An extraction complicated by lateral and medial pterygoid tethering of a fractured maxillary tuberosity. British Dental Journal 2005; 198(9): 543-544.

Barsoumian R, Kuehn DP, Moon JB et al. An anatomic study of the tensor veli palatini and dilatator tubae muscles in relation to eustachian tube and velar function. Cleft Palate-Craniofacial Journal 1998; 35(2): 101-110.

Erikssott I, Hakansson H. Unilateral fracture of the pterygoid process. Report of a case. Oral Surgery Oral Medicine Oral Pathology 1979; 47(2): 127-130.

Noone RB, Randall P, Stool SE et al. The effect on middle ear disease of fracture of the pterygoid hamulus during palatoplasty. Cleft Palate-Craniofacial Journal 1973; 10: 23-33.

Kane AA, Lo LJ, Yen BD et al. The effect of hamulus fracture on the outcome of palatoplasty: A preliminary report of a prospective, alternating study. Cleft Palate-Craniofacial Journal 2000; 37(5): 506-511.

Abe M, Murakami G, Noguchi M et al. Variations in the tensor veli palatini muscle with special reference to its origin and insertion. Cleft Palate-Craniofacial Journal 2004; 41(5): 474-484. 
Okada R, Muro S, Eguchi K et al. The extended bundle of the tensor veli palatine: anatomic considerations of the dilating mechanism of the eustachian tube. Auris Nasus Larynx 2018; 45 (2): 265-272. https://doi.org/10.1016/j.anl.2017.05.014

Oz U, Orhan K, Aksoy S et al. Association between pterygoid hamulus length and apnea hypopnea index in patients with obstructive sleep apnea: a combined three-dimensional cone beam computed tomography and polysomnographic study. Oral Surg. Oral Med. Oral Pathol. Oral Radiol. 2016; 121: $330-9$.

West OC, Mirvis SE, Shanmuganathan K. Transsphenoid basilar skull fracture: CT Patterns. Radiology 1993; 188: 329-338.

Oliveira DM, Vasconcellos RJH, Laureano Filho JR et al. Fracture of the coronoid and pterygoid processes by firearms: Case report. Brazilian Dental Journal 2007; 18(2): 168-170.

An J, Dai F, Sun Z et al. Classification and characteristics of pterygoid process fracture associated with maxillary transverse fracture. Oral Surgery, Oral Medicine, Oral Pathology and Oral Radiology 2014; 117(2): 243-252.

Imai T, Sukegawa S, Kanno T et al. Mandibular fracture patterns consistent with posterior maxillary fractures involving the posterior maxillary sinus, pterygoid plate or both: CT characteristics. Dentomaxillofac Radiol. 2014; 43(2): 20130355. doi: 10.1259/dmfr.20130355.

Truong A Q, O'Brien D C, Strong E B et al. Lateral pterygoid plate fractures associated with mandible fractures. JAMA Facial Plast Surg. 2014; 16(6): 437-9. doi: 10.1001/jamafacial.2014.645.

Winegar B A, Murillo H, Tantiwongkosi B. Spectrum of critical imaging findings in complex facial skeletal trauma. Radiographics 2013; 33(1): 3-19. doi: 10.1148/rg.331125080

Jain A, Nimonkar P, Bhola N et al. Does Hamulotomy during Palatoplasty Have Any Effect on Hearing Ability in Nonsyndromic Cleft Palate Patients? A Prospective, Single Blind, Comparative Study. Hindawi Publishing Corporation Scientifica 2016, 1: 1-6. http://dx.doi.org/10.1155/2016/9641303

Sasaki T, Imai Y, Fujibayashi T. A case of elongated pterygoid hamulus syndrome. Oral Diseases 2001; 7: 131-133.

Roode G J, Bütow K W. Pterygoid hamulus syndrome - undiagnosed. South African Dental Journal 2014; 69(2): 70-71.

Eyrich GK, Locher MC, Warnke $\mathrm{T}$ et al. The pterygoid hamulus as a pain-inducing factor. International. Journal of Oral Maxillofacial Surgery 1997; 26: 275-277.

Cho J Y, Cheon K Y, Shin D W et al. Pterygoid hamulus bursitis as a cause of craniofacial pain: a case report. Journal of the Korean Association of Oral and Maxillofacial Surgeons 2013; 39(3): 134-138.

Shetty S S, Shetty P, Kiran Shah P K et al. Pterygoid Hamular Bursitis: A Possible Link to Craniofacial Pain. Hindawi 2018; 2018: 1-5. https://doi.org/10.1155/2018/5108920 
Komarnitki I, Skadorwa T, Chloupek A. Radiomorphometric assessment of the pterygoid hamulus as a factor promoting the pterygoid hamulus bursitis. Folia Morphologica 2019; 78: 1-16. DOI 10.5603/FM.a2019.0049

Kronman JH, Padamsee M, Norris LH. Bursitis of the tensor veli palatini muscle with an osteophyte on the pterygoid hamulus. Oral Surgery Oral Medicine Oral Pathology 1991; 71(4): 420-2.

Dupont JS Jr, Brown CE. Comorbidity of pterygoid hamular area pain and TMD. Cranio 2007; 25(3): $172-6$. 